\title{
Seguridad Humana y Derecho Internacional Público
}

\author{
Human Security and Public International Law
}

\section{Dorothy EsTRADA TANCK}

Doctora en Derecho Internacional por el Instituto Universitario Europeo*

Dorothy.Estrada-Tanck@eui.eu

Resumen: Este estudio sostiene que la seguridad humana guarda una relación conceptual con el derecho internacional público y que además en años recientes se han desarrollado diversas expresiones prácticas de la seguridad humana relevantes para esta rama del derecho que merecen ser estudiadas con mayor detalle. A ese respecto, el enfoque central de este texto no es proporcionar evidencia total de la materialización normativa de la seguridad humana en las fuentes tradicionales del derecho internacional público, sino más bien profundizar en el análisis de las implicaciones normativas de la seguridad humana, especialmente en su simbiosis con los derechos humanos reconocidos por el derecho internacional. Una de las preocupaciones centrales del derecho internacional público contemporáneo es, precisamente, el área del derecho internacional de los derechos humanos. Como tal, se hace referencia a las fuentes del derecho internacional público y se detalla y aclara la manera en que la seguridad humana se relaciona con ellas en el campo concreto de los derechos humanos

Palabras clave: seguridad humana, derecho internacional público, derecho internacional de los derechos humanos, derechos humanos, vulnerabilidad.

\begin{abstract}
This study argues that human security holds a conceptual relationship with public international law and that in recent years several practical expressions of human security have been developed in a manner relevant to this area of the law and, thus, they deserve to be analyzed in further detail. In this respect, the main emphasis of this text is not to provide integral evidence of the normative materialization of human security in the traditional sources of public international law, but rather to deepen in the examination of the normative implications of human security, particularly in its synergies with human rights recognized internationally. One of the main concerns of modern public international law is, precisely, the area of international human rights law. As such, reference is made to the sources of public international law and closer attention is provided to the concrete ways in which human security relates to them in the sphere of human rights.
\end{abstract}

Keywords: human security, public international law, international human rights law, human rights, vulnerability.

Sumario: I. ¿QUÉ ES LA SEGURIDAD HUMANA?; II. LA SEGURIDAD HUMANA Y LAS FUENTES DE DERECHO INTERNACIONAL PÚBLICO; III. DERECHO INTERNACIONAL PÚBLICO, RIESGO Y VULNERABILIDAD; III.1 Derecho Internacional de los Derechos Humanos y Seguridad Humana; A. Riesgos socio-económicos y pobreza; B. Medidas Precautorias, Provisionales y Temporales; C. Grupos especialmente vulnerables, i. Obligaciones reforzadas de protección, ii. Discriminación indirecta e inversión de la carga probatoria; D. Estereotipo y Daño Colectivo: Respuestas Colectivas; IV. ALGUNAS CONCLUSIONES: LA SEGURIDAD HUMANA COMO CATALIZADOR DEL DERECHO INTERNACIONAL PÚBLICO.

* Autora del libro Human Security and Human Rights under International Law. The Protections Offered to Persons Confronting Structural Vulnerability, Hart Publishing, Oxford, 2016 


\section{I. ¿QUÚ ES LA SEGURIDAD HUMANA?}

$\square$

1 concepto de seguridad humana irrumpe en el escenario internacional a través de su articulación a inicios de los noventas por el Programa de Naciones Unidas para el Desarrollo (PNUD), al final de la Guerra Fría $^{1}$, y desarrollado después por la Comisión de Seguridad Humana (CSH) -grupo de expertos independientes nombrados por el Secretario General de Naciones Unidas- en 2003.

En términos generales, de acuerdo con la CSH, puede afirmarse que la seguridad humana se basa en los ejes de libertad frente al temor, frente a la miseria y para vivir en dignidad, y significa:

«la protección del núcleo vital de todas las vidas humanas de forma que se potencien las libertades humanas y la realización humana... significa proteger las libertades fundamentales-libertades que son la esencia de la vida-... proteger a las personas de las amenazas y situaciones críticas (severas) y omnipresentes (generalizadas). Significa utilizar procesos que se basan en las fortalezas y aspiraciones de la gente. Significa crear sistemas políticos, sociales, ambientales, económicos, militares y culturales que en conjunto proporcionen a las personas los elementos básicos de la supervivencia, el sustento y la dignidad»².

Así pues, la postura de seguridad humana intenta abordar los riesgos que enfrentan las personas y las comunidades, en lugar de los Estados como en las concepciones tradicionales de 'seguridad nacional' o 'seguridad militar' defendidas en las relaciones internacionales y el derecho internacional público clásico. En ese sentido, busca priorizar la atención a riesgos tales como los peligros ambientales, la pobreza, las enfermedades infecciosas, los conflictos violentos intra-estatales y no sólo inter-estatales, el hambre y la falta de agua, la violencia contra las mujeres, o la delincuencia organizada transnacional. Por ello, el PNUD desde su Informe sobre Desarrollo Humano de 1994 propuso siete formas principales de seguridad humana: la seguridad de la salud o seguridad sanitaria, la seguridad económica, la seguridad ambiental, la seguridad

1 PNUD, Informes sobre Desarrollo Humano (1993 y 1994), disponibles en http://hdr.undp.org/ en/reports/

2 Comisión de Seguridad Humana, Human Security Now (CSH, Nueva York, 2003) 4 (traducción propia; énfasis añadido). 
de la comunidad, la seguridad política, la seguridad personal y la seguridad alimentaria $^{3}$, que posteriormente la CSH desarrollaría con mayor detalle.

Tanto el informe del PNUD como el de la CSH colocaron a los derechos humanos como uno de sus pilares fundamentales y abogaron por un enfoque centrado en la persona en relación con los peligros y riesgos que crean vulnerabilidades compartidas e interrelacionadas para las personas de todo el mundo ${ }^{4}$.

Asimismo, el Segundo Informe del Secretario General de NU sobre Seguridad Humana, de abril de 2012, refleja el consenso estatal sobre una perspectiva compartida del concepto y pone de relieve que la seguridad humana «no hace ninguna distinción entre los derechos civiles, políticos, económicos, sociales y culturales y, en consecuencia aborda las amenazas... de una manera multidimensional e integral» ${ }^{5}$. Dicho informe fue avalado después por la Asamblea General de NU (AGNU) que en el mismo año 2012 llega a un momento culmen al acordar un 'entendimiento común' de la seguridad humana como comprehensiva y multidimensional y, por tanto, valiosa para la consecución de todos los derechos humanos por igual, visión que se confirmaría en el Tercer Informe del Secretario General de NU sobre Seguridad Humana de $2013^{6}$. Es así que la seguridad humana aparece como el primer concepto a nivel internacional que une de forma articulada tres propuestas centrales del derecho internacional contemporáneo: la seguridad, el desarrollo y los derechos humanos, las conecta y llena las lagunas existentes entre ellas ${ }^{7}$, y como tal puede jugar un

3 PNUD, Informe sobre Desarrollo Humano, Nuevas Dimensiones de la Seguridad Humana (1994), 23 25, disponible en <http://hdr.undp.org/en/media/hdr_1994_en_chap2.pdf>; y Human Security Now, op. cit., 4 (traducción propia; énfasis agregado).

4 FukUdA-ParR, «New Threats to Human Security in the Era of Globalization», en Chen, L. et al. (eds.), Human Insecurity in a Global World, Harvard University Press, Harvard, 2003, 1-13 (traducción propia). Véase también cap. I del Informe especial sobre seguridad bumana en la ciudad de México 2006-2008, Comisión de Derechos Humanos del Distrito Federal, México, 2008.

5 Segundo Informe del Secretario General de NU sobre Seguridad Humana, Asamblea General de NU, A/66/763, 'Seguimiento de la Resolución 64/291 de la Asamblea General sobre Seguridad Humana. Informe del Secretario General' (5 de abril de 2012), para. 26 (énfasis agregado).

6 AGNU, 'Seguimiento del Párrafo 143 sobre Seguridad Humana del Resultado de la Reunión Global de 2005', A/Res/66/290, 10 de septiembre de 2012, paras. 3 a) y c); Tercer Informe del Secretario General de NU sobre Seguridad Humana, 'Seguimiento a la Resolución 66/290 de la Asamblea General sobre Seguridad Humana', A/68/685 (23 de diciembre de 2013).

7 En este sentido, véase KleIN GoldeWIJK, B., «Why Human? The Interlinkages between Security, Rights and Development», Security and Human Rights, 19, 1 (2008), 24-37; y Banco Mundial, Informe Mundial sobre Desarrollo 2011: Conflicto, Seguridad y Desarrollo (11 de abril de 2011) 16. 
papel protagónico en varios campos del derecho internacional público, como lo demuestran algunos estudios recientes ${ }^{8}$.

El presente texto se centrará en analizar cómo este concepto construido por la comunidad internacional se vincula con el Derecho Internacional Público y las implicaciones de esta relación, particularmente en el ámbito de los derechos humanos.

\section{LA SEGURIDAD HUMANA Y LAS FUENTES DE DERECHO INTERNACIONAL PÚBLICO}

De acuerdo con el artículo 38.1 del Estatuto de la Corte Internacional de Justicia (CIJ), tradicionalmente considerado como el fundamento de las fuentes del derecho internacional público, la Corte para decidir conforme al derecho internacional las controversias que le sean sometidas, deberá aplicar:

a) las convenciones internacionales, sean generales o particulares, que establecen reglas expresamente reconocidas por los Estados litigantes;

b) la costumbre internacional como prueba de una práctica generalmente aceptada como derecho;

c) los principios generales de derecho reconocidos por las naciones civilizadas;

d) las decisiones judiciales y las doctrinas de los publicistas de mayor competencia de las distintas naciones, como medio auxiliar para la determinación de las reglas de derecho...?.

Generalmente, las primeras tres se consideran como fuentes primarias del derecho internacional dada la mención específica en el inciso d) de las

8 Véase, eg, Oberleitner, G., «Human Security: A Challenge to International Law?», Global Governance, 11 (2005), 185-86; FERNÁNDEZ PEREIRA, J. P., La seguridad bumana: un derecho emergente, Ariel, Barcelona, 2006; GARCÍA, C. y RodrigO, Á. J., «La necesidad de redefinir la seguridad: seguridad humana, seguridad colectiva y derecho internacional», en GARCía, C. y Rodrigo, Á. J. (eds.), La seguridad comprometida. Nuevos desafíos, amenazas y conflictos armados, Tecnos, Madrid, 2008, 205-228; Sunga, L. S, «The Concept of Human Security: Does it Add Anything of Value to International Legal Theory or Practice?», en FRICK, $M^{a}$ L. y OBERPRANTACHER, A. (eds.), Power and Fustice in International Relations. Interdisciplinary Approaches to Global Challenges, Ashgate, Reino Unido y USA, 2009; y muy recientemente NASU, H., «Human Security and International Law: The Potential Scope for Legal Development within the Analytical Framework for Security», en Footer, M. E.; SCHMidT, J.; White, N. D. y DaVIES-Bright, L. (eds.), Security and International Law, Hart Publishing, 2016, 25.

9 El Estatuto de la Corte Internacional de Justicia (CIJ), está anexado a la Carta de las Naciones Unidas de 1945, de la que forma parte integral. 
decisiones judiciales y la doctrina, como medios «auxiliares» para las determinaciones normativas de la Corte.

Es de hacerse notar, no obstante, que esta clasificación ortodoxa ha sido criticada desde la perspectiva feminista. Hilary Charlesworth y Christine Chinkin discuten que esta categorización formal de fuentes y su defensa por los Estados, abogados y académicos ha dejado al margen otras formas de hacer derecho, así como a actores y procedimientos que impactan en la creación cotidiana del derecho y con ello les ha colocado fuera del campo del derecho, normalmente en detrimento de las mujeres. En efecto, el tema de violencia contra las mujeres revela la dificultad de modificar puntos de vista convencionales y tradicionales sobre las fuentes (válidas) del derecho internacional público ${ }^{10}$. Sin embargo, para los propósitos de este texto, se apelará a la categorización clásica con el fin de utilizar estas fuentes como punto de partida para explorar con base en ellas el potencial del concepto de seguridad humana para apuntar a fuentes de evidencia «no tradicionales» y a argumentaciones más integrales del derecho internacional de los derechos humanos.

Así, a la luz de las fuentes del derecho internacional público de la CIJ, se puede recordar que el contenido de la Declaración Universal de los Derechos Humanos (DUDH) y los dos Pactos Internacionales de 1966 -de Derechos Civiles y Políticos, y de Derechos Económicos, Sociales y Culturales, conocidos como la «Carta Internacional de Derechos Humanos»- se consideran como vinculantes, ya sea directamente a través de las obligaciones adoptadas por los Estados parte de tratados internacionales de derechos humanos o indirectamente a través del derecho internacional consuetudinario o de los principios generales del derecho. Esto que es relevante en el sentido de determinar los derechos y obligaciones de los Estados que no son parte de tratados internacionales de derechos humanos, así como los derechos de personas individuales o grupos contemplados en el derecho internacional consuetudinario. Otra consecuencia importante de esta afirmación es que 'el reconocimiento de los derechos humanos en el derecho consuetudinario permite, no sólo a los Estados que no son parte, sino también a los Estados parte, acceder a recursos y remedios del derecho internacional que los tratados no proporcionan' ${ }^{11}$.

10 Charlesworth, H. y Chinkin, C., The Boundaries of International Law. A Feminist Analysis, Juris Publishing, Manchester University Press, UK, 2000, 70-79.

11 Schachter, O., International Law in Theory and Practice, Martinus Nijhoff Publishers, Holanda, 1991, 335. (Traducción propia). 
A ese respecto, todos los derechos humanos contenidos en estos instrumentos jurídicos, como un estándar mínimo, forman parte esencial del derecho internacional público, y algunos de ellos, como la prohibición absoluta de la tortura, incluso constituyen derechos imperativos del derecho internacional general, esto es, normas de ius cogens. Como es bien sabido, el artículo 53 de la Convención de Viena sobre el Derecho de los Tratados de 1969 define a la norma de ius cogens como 'una norma aceptada y reconocida por la comunidad internacional de Estados en su conjunto como norma que no admite acuerdo en contrario y que sólo puede ser modificada por una norma ulterior de derecho internacional general que tenga el mismo carácter'. Así, dichas normas disfrutan de un carácter absoluto, son no-derogables y son oponibles erga omnes, esto es, su cumplimiento puede reclamarse a toda la comunidad internacional y no sólo a un Estado específico. Como la CIJ ha reconocido, la razón detrás de esta preocupación legítima de todos los Estados es la naturaleza del asunto en cuestión: 'En vista de la importancia de los derechos involucrados, todos los Estados pueden tener un interés normativo en su protección; son obligaciones erga omnes ${ }^{12}$.

Siguiendo esta línea de pensamiento, también se ha discutido que las normas de ius cogens -observando una lógica similar al fundamento del derecho internacional consuetudinario, pero con un carácter jurídicamente vinculante en un grado más alto- son inmunes a las objeciones persistentes de cualquier Estado o grupos de Estados minoritarios. En este sentido,

«parece claro que existen elementos del actual sistema jurídico internacional que no se basan en el consentimiento de los Estados involucrados... Las normas ius cogens son vistas... como una clase de derechos superinternacionales, que superan otras formas de derecho y sólo pueden ser cambiadas por la evolución de una nueva norma de ius cogens. Además, estas normas son capaces de [ser] vinculantes para todo y contra todo (no sólo para y contra aquellos que han consentido la creación de las normas) $\gg^{13}$.

Las normas de ius cogens también han sido examinadas a la luz de los derechos humanos y se ha concluido que:

«En el contexto del lenguaje radical de los derechos humanos, ciertos principios de derechos bumanos son reconocidos como normas imperativas ius

12 CIJ, Caso relativo a la Barcelona Traction, Light and Power Company, Limited, Bélgica v España, Sentencia del 5 de febrero de 1970, para 33 (traducción propia). Énfasis agregado.

13 Moisés Peñalver, E., «The Persistent Problem of Obligation in International Law», Stanford Fournal of International Law, 36 (2000), 282. (Traducción propia y énfasis agregado). 
cogens del derecho internacional. Las normas ius cogens son principios fundamentales del derecho internacional consideradas vinculantes para todos los Estados, que no permiten excepciones ${ }^{14}$.

Así pues, se puede argumentar que ciertos derechos humanos, y ciertamente al menos el 'contenido central' o 'núcleo' de todos los derechos humanos, incluyendo los derechos económicos, sociales y culturales (DESC), han alcanzado el nivel de ius cogens ${ }^{15}$. La pregunta sobre si existe suficiente evidencia en esta dirección o si (algunos) derechos humanos sólo tienen estatus de derecho internacional consuetudinario o forman parte de los principios generales del derecho como fuentes primarias del derecho internacional (y no se configuran aún como normas de ius cogens), constituye un debate que no será el centro de este texto. En todo caso, queda claro que las normas jurídicas internacionales que se refieren a los derechos inalienables de las personas y a la protección de los seres humanos constituyen hoy en día uno de los puntos de referencia fundamentales de todo el derecho internacional público en general. Mientras que el derecho internacional tradicional se ha considerado como el que regula principalmente las relaciones entre Estados, Antonio Cassese ha resaltado que el desarrollo histórico muestra que 'el derecho internacional abarca cada vez más temas derechos humanos y vincula a los Estados no sólo entre ellos mismos, sino también a los Estados con respecto a las personas sujetas a su jurisdicción'16.

De forma similar, el Juez Cançado Trindade ha desarrollado extensivamente el concepto del 'derecho común de la humanidad' o el 'derecho internacional para la humanidad' desde la perspectiva académica y con base en la jurisprudencia regional e internacional y la práctica jurídica ${ }^{17}$. Esta posición se confirma con el trabajo de Ruti G Teitel, quien ha sostenido que a partir del final de la Guerra Fría se ha ido construyendo un cambio hacia la 'perspectiva

14 Humes-Schulz, S., «Limiting Sovereign Immunity in the Age of Human Rights», Harvard Human Rights fournal, 21 (2008), 110. (Traducción propia y énfasis agregado).

15 En este sentido, véase los argumentos convincentes sobre el derecho a la salud como norma de ius cogens presentados en GunN, P. C., «Health Care Refugees», Loyola University Chicago International Law Review, 6 (2009), 339. Veáse también GALTUNG, I., Lawyers or Liars? Is World Hunger Suable in Court?, Tesis Doctoral en Derecho, Instituto Universitario Europeo, Florencia, 2011, que argumenta que el núcleo central del derecho a la alimentación, específicamente, la protección contra el hambre, es una norma de ius cogens.

16 CASSESE, A., International Law, $2^{\mathrm{a}}$ ed., Oxford University Press, Oxford, 2005, 45.

17 Véase el clásico CANÇADO Trindade, A. A., International Law for Humankind: Towards a New fus Gentium, Martinus Nijhoff Publishers, Holanda, 2010. 
de seguridad humana', denominada así por basarse en las intersecciones entre el derecho internacional de los derechos humanos, el derecho internacional humanitario y el derecho penal internacional, como los derechos bumanitarios y bumanizantes más generales, y consecuentemente ha identificado expresiones normativas y jurisprudenciales de un marco de seguridad humana aplicado en la práctica ${ }^{18}$.

$\mathrm{Al}$ mismo tiempo, se debe admitir que el marco jurídico internacional de derechos humanos por sí mismo presenta lagunas y deficiencias que se identifican, por ejemplo, en el caso de personas sujetas a estereotipación colectiva en razón de su pertenencia a algún grupo, incluyendo el caso de la población gitana, o las personas solicitantes de asilo, así como en el caso más general de las personas migrantes indocumentadas y otras no ciudadanas, particularmente las mujeres y niñas, como se destaca más adelante en este texto. Es en estas instancias cuando la seguridad humana puede jugar su papel más poderoso. En ese contexto sostengo que la seguridad humana es un concepto orientador y complementario que puede ampliar las fronteras del derecho internacional y que -por utilizar el lenguaje de Hilary Charlesworth y Christine Chinkin-, ofrece herramientas interpretativas de los derechos humanos que son más integrales y expansivas y por ello tiene la capacidad de reforzar las medidas protectoras para personas y grupos viviendo en condiciones de vulnerabilidad.

\section{Derecho Internacional Público, Riesgo y Vulnerabilidad}

$\mathrm{Al}$ pensar en las dimensiones normativas y jurídicas de la seguridad, de inmediato surge la pregunta de ¿cómo el Derecho responde frente al riesgo? Hablando en general, si analizamos la agenda de la seguridad humana y sus elementos centrales de 'riesgo' y 'vulnerabilidad', tales dimensiones se han englobado de una u otra manera en los principios del derecho internacional ${ }^{19}$. El derecho internacional como posición general ha tomado en cuenta el riesgo y vulnerabilidad con un enfoque centrado en la persona, aun cuando no siempre defina dichas concepciones en detalle sino que las deje abiertas a la

18 Teitel, R. G, Humanity's Law, Oxford University Press, Oxford, 2011, 35-69; 105-38 y el análisis del 'cambio hacia la perspectiva de seguridad humana' de la justicia global, en 139-64.

19 Para una serie de ensayos en el tema de derecho y seguridad, véase SCHEININ, M., et al., Law and Security - Facing the Dilemmas, EUI Working Paper Law 2009/11, Instituto Universitario Europeo, Florencia, 2009. 
interpretación jurídica de las entidades competentes. De hecho, el riesgo y la vulnerabilidad se han aplicado por el derecho internacional hacia situaciones, personas y grupos considerados dignos de una cierta obligación reforzada dirigida a prevenir daños, proteger al sujeto afectado si el riesgo se materializa o conceder reparación cuando ya se ha producido un menoscabo como resultado de una situación insegura. Pensemos, por ejemplo, en las normas sobre deberes de rescate en el mar, o aquellas dirigidas a la protección de grupos concretos de personas, tales como niños y niñas en conflictos armados, o mujeres sujetas a discriminación y violencia ${ }^{20}$.

Lyal S. Sunga ha destacado que una noción de seguridad humana que esté completamente informada por el derecho internacional de los derechos humanos, el derecho internacional humanitario, el derecho penal internacional y el derecho internacional de refugiados, así como por las normas jurídicas internacionales que prohíben el uso de la fuerza en relaciones internacionales, probablemente resulte más valiosa a largo plazo, que una noción de seguridad humana que no reúna estas condiciones, ya que estas áreas del derecho personifican la voluntad política de los Estados ${ }^{21}$. Algunos elementos de estas cuatro ramas del derecho internacional público, generalmente se consideran como el bloque de normas protectoras de los derechos humanos -un «derecho internacional para la humanidad»- que intersecta y se superpone con la seguridad humana en su enfoque centralizado en la persona humana y en las vulnerabilidades estructurales y generalizadas que afectan a los seres humanos.

De hecho, el Juez Cançado Trindade ha considerado de manera similar que las tres principales venas de protección de la persona humana dentro del derecho internacional, especialmente el derecho internacional de los derechos humanos, el derecho internacional humanitario y el derecho internacional de los refugiados, convergen en su preocupación por la seguridad de la persona,

20 Veáse el Convenio Internacional para la Seguridad de la Vida en el Mar de Naciones Unidas y el Convenio Internacional sobre Búsqueda y Salvamento Marítimos, y las obligaciones de rescate en el mar y cooperación internacional contenidas en los mismos, y complementadas por la Convención de Naciones Unidas sobre el Derecho del Mar de 1982, especialmente relevante para la situación actual de miles de personas migrantes y potenciales refugiados del Medio Oriente y África que intentan llegar por mar a países europeos. Véase también el Protocolo Optativo a la Convención de los Derechos del Niño sobre Niños en Conflicto Armado y la Convención de NU sobre la Eliminación de Todas las Formas de Discriminación contra la Mujer.

21 Véase Sunga, L. S., «The Concept of Human Security: Does it Add Anything of Value to International Legal Theory or Practice?», op. cit., 131-48. 
y en consecuencia la unión de estas tres ramas del derecho puede considerarse de hecho como la 'seguridad humana'22. Ciertamente, la seguridad humana tiene el potencial de atraer bajo un marco general común los valores centrales, las metas y las normas jurídicas del Derecho Internacional Público sobre protección de la persona humana. Construyendo desde esta idea, el objetivo aquí es explorar cómo esta concepción puede provocar nuevas formas teóricas de comprender las expresiones jurídicas internacionales y que sean operativas en formas relevantes para el derecho internacional en la práctica.

En este contexto, pueden encontrarse elementos y expresiones de la seguridad humana, explícitamente o implícitamente, en las fuentes primarias tradicionales del Derecho Internacional Público -tratados, costumbre internacional, principios generales del derecho- así como en las fuentes secundarias de jurisprudencia y doctrina, o incluso en las normas de ius cogens. Como ya se adelantaba, la preocupación principal de este texto no es prioritariamente definir las implicaciones jurídicas de la seguridad humana desde el punto de vista de dichas fuentes, sino más bien, primeramente, hacer explícitas las intersecciones entre el concepto (meta-jurídico) de la seguridad humana y el entendimiento jurídico de los derechos humanos internacionales. Y en segundo lugar, concretar las formas en las que esta interacción pueda desarrollarse más y beneficiar tanto a la seguridad humana como a los derechos humanos. En este sentido, la seguridad humana se explora en su potencial como una herramienta hermenéutica para el entendimiento jurídico de los derechos humanos.

Considerando el enfoque jurídico internacional sobre riesgos relevantes para la seguridad humana, debe también hacerse referencia a la relación entre seguridad humana y derecho internacional humanitario (DIH). Siendo esta rama del Derecho Internacional Público el marco normativo que regula el conflicto armado, algunas de las situaciones que el DIH visualiza coinciden o se superponen con la preocupación de la seguridad humana. Pensemos también en los aspectos humanitarios de ciertas normas, por ejemplo, las Resoluciones 1325 y 1820 del Consejo de Seguridad de Naciones Unidas (CSNU) sobre Mujeres, Paz y Seguridad, relativas a mujeres en situaciones de conflicto armado y post-conflicto ${ }^{23}$. Sin embargo, dado que el DIH es

22 Cançado Trindade, A. A., A bumanizaçao do direito internacional, Editora del Rey, Brazil, 2006, 322-24.

23 CSNU, Resolución 1325, S/Res/1325 (31 de octubre de 2000); y CSNU, Resolución 1820, S/ Res/1820 (19 de junio de 2008). 
considerado como un régimen de excepción donde los estándares aplicables son más estrechos, se estima que la perspectiva más amplia de los estándares generales del derecho internacional de los derechos humanos (DIDH) se ajusta mejor a la noción holística de la seguridad humana defendida en este texto, como una que contiene en su centro la protección de todos los derechos humanos: civiles, políticos, económicos, sociales y culturales. A la luz de las vulnerabilidades estructurales estudiadas por la seguridad humana y presentes en diferentes niveles en todas las sociedades, se ha preferido la perspectiva del DIDH, precisamente como un marco jurídico más extenso que abre puertas a preguntas innovadoras en términos de las posibilidades y limitaciones de la noción de seguridad humana respecto del derecho internacional público.

Por ello se presentan algunas reflexiones sobre los niveles de encuentro entre seguridad humana y derechos humanos y su efecto en el Derecho Internacional Público, concretamente en la rama específica del DIDH.

\section{III.1. Derecho Internacional de los Derechos Humanos y Seguridad Humana}

Utilizando los conceptos de riesgo y vulnerabilidad como puntos de referencia para el análisis, podemos encontrar en diferentes instrumentos jurídicos de derechos humanos lo que podría denominarse un 'enfoque de seguridad humana'. Para un análisis más sistemático, estas expresiones jurídicas se agrupan con base en la materia que abordan, en las siguientes secciones:

\section{A. Riesgos socio-económicos y pobreza}

Los Principios Rectores sobre la extrema pobreza y los derechos bumanos, adoptados en 2012 por el Consejo de Derechos Humanos de NU, resaltan que:

«Las personas que viven en situación de pobreza generalmente están expuestas a riesgos de violencia institucional e individuales y ven amenazadas su integridad física por parte de funcionarios del Estado y actores privados, que les hacen vivir en constante miedo e inseguridad. La continua exposición $\mathrm{y}$ vulnerabilidad a la violencia afecta la salud mental y física de la persona y perjudica su desarrollo económico y su capacidad de escapar la pobreza. Aquellos que viven en situación de pobreza, con poca o nula independencia económica, tienen menos posibilidades de encontrar seguridad y protección... Asimismo, la pobreza es una causa de enfermedades prevenibles, la mala salud, 
los altos índices de mortalidad y la baja expectativa de vida, no sólo por la alta exposición a la violencia sino también por privaciones materiales y sus consecuencias, como la falta de alimento, agua salubre y saneamiento» ${ }^{24}$.

Expresados en el lenguaje y espíritu de la seguridad humana, algunos derechos económicos, sociales y culturales (DESC) también abren las puertas a la protección reforzada de las personas en contextos de vulnerabilidad socioeconómica estructural. El derecho de 'todos y todas' a la protección contra el hambre, por ejemplo, está específicamente contemplado como el contenido del derecho a la alimentación en el artículo 11.2 del Pacto Internacional de Derechos Económicos, Sociales y Culturales de 1966 (PIDESC) ${ }^{25}$. En el desarrollo posterior de este derecho, el Relator Especial de NU sobre el Derecho a la Alimentación ha propuesto criterios para garantizar la 'seguridad alimentaria' y una vida digna libre de hambre y libre de miedo ${ }^{26}$.

De forma similar, el riesgo se contempla especialmente en la Carta Social Europea Revisada de 1996 (CSER) que incluye, en su artículo 30, el derecho de la protección contra la pobreza y la exclusión social. Tal derecho se traduce en una obligación del Estado de tomar medidas que promuevan el acceso efectivo 'de personas que viven en o estén en riesgo de vivir en situación de exclusión social o pobreza, así como sus familias... al empleo, vivienda, capacitación, educación, cultura y asistencia social y médica' ${ }^{27}$. Debe precisarse, sin embargo, que varios Estados Miembros de la Carta Social Europea original de 1961, no han adoptado aún la CSER, entre ellos España.

Por otro lado, en el ámbito académico, distintos subtipos de la seguridad humana relativos a la dimensión socio-económica de la seguridad, han sido

24 Consejo de Derechos Humanos de UN, Principios Rectores sobre la extrema pobreza y los derechos bumanos (contenidos en el Borrador Final emitido por la Relatora Especial sobre la pobreza extrema y los derechos humanos, Magdalena Sepúlveda Carmona, Resolución A/HC/21/39 de la Asamblea General de NU, 18 de julio de 2012), aprobados por el Consejo de Derechos Humanos de NU en la Resolución 21/11 del 27 de septiembre de 2012, para 63.

25 El Pacto Internacional de Derechos Económicos, Sociales y Culturales (PIDESC), fue adoptado y abierto a firma y ratificación de la Asamblea General mediante la Resolución 2200A (xxI) del 16 de diciembre de 1966 y entró en vigor el 23 de marzo de 1976.

26 Véase, eg, el comunicado de prensa en la visita de Estado a Camerún, de Olivier De Schutter, Relator Especial de NU sobre el Derecho a la Alimentación, 'Cameroon: Stricter Taxes for Companies Drawing on Natural Resources to Better Tackle Hunger - UN Special Rapporteur', el 23 de julio de 2012, disponible en www.ohchr.org/EN/NewsEvents/Pages/DisplayNews.aspx? NewsID $=12385 \&$ LangID $=\mathrm{E}$

27 La Carta Social Europea Revisada, CETS No 163, abierta a firma por los estados miembros del Consejo de Europa el 3 de mayo de 1996 y entrada en vigor el 1 de julio de 1999. 
estudiados desde la perspectiva del derecho internacional de los derechos humanos, por ejemplo, en el caso de la seguridad sanitaria ${ }^{28}$.

El Tribunal Europeo de Derechos Humanos (TEDH) trató con otro tema cercano al campo de la seguridad humana, relacionado con la dimensión ambiental y la vulnerabilidad experimentada en el contexto de la pobreza urbana ${ }^{29}$. En 2004 en el caso de Önerylidiz v Turquía, el Tribunal enfatizó la obligación positiva del Estado de tomar medidas para prevenir riesgos, especialmente en el caso de peligros para la vida, una vez que conocía de la existencia de dichos peligros. El caso involucró la explosión de un basurero municipal que resultó en la muerte de 39 personas que vivían en un asentamiento irregular, hechos que condujeron a que el TEDH concluyera que 'había información práctica disponible que indicaba que los habitantes de ciertas zonas pobres... se enfrentaban a la amenaza de su integridad física como efecto de los descuidos técnicos sobre el basurero municipal'. Además, enfatizó que 'las autoridades turcas de varios niveles sabían o deberían haber sabido que había un riesgo real e inmediato para un número de personas que vivían cerca del... basurero municipal ${ }^{130}$.

En esta misma línea, en los casos de las masacres de Mapiripán y de Ituango, de 2005 y 2006, ambos en contra de Colombia, la Corte Interamericana de Derechos Humanos (CIDH) desarrolló la 'doctrina del riesgo conocido' o 'del riesgo creado evitable y previsible', construida con base en la jurisprudencia previa del sistema europeo de derechos humanos y elementos incorporados de la realidad interamericana ${ }^{31}$. Este concepto del 'riesgo conocido' se recoge para ilustrar la relación entre violaciones potenciales de los derechos humanos -derechos humanos 'en riesgo'-, y aquellas violaciones que realmente se ma-

28 Cook, Rebecca J, 'Human Rights Dimensions of Health Security' (2003) 97 American Society of International Law Proceedings, 101-06.

29 Sobre seguridad humana y pobreza urbana, véase LiotTa, P. H. y BiLgin, A., «Why Human Security? The Case for Resilience in an Urban Century», en MARTIN, M. y OwEN, T. (eds.), Routledge Handbook of Human Security, Routledge, USA-Canada, 2014, 109-22.

30 TEDH, Öneryildiz v Turquía (GC), Appl No 48939/99, sentencia del 30 noviembre 2004, paras. 98 y 101 (traducción propia). Énfasis agregado.

31 Véase CIDH, Caso de la Masacre de Mapiripán v Colombia, del 15 de septiembre de 2005, Serie C, No 134, y el Caso de la Masacre de Ituango v Colombia, del 1 de julio de 2006, Serie C, No 148, en los que la Corte analiza intervenciones paramilitares frente a la falta de evidencia de actuación directa de funcionarios del gobierno, y no obstante, concluye que existe responsabilidad del Estado sobre la base de que hubo complicidad respecto al 'riesgo conocido'. En la misma línea, véase también CIDH, Caso de la Masacre de Pueblo Bello v Colombia, del 31 de enero de 2006, Series C, No 140. 
terializan debido a la falta de atención por parte del Estado a los riesgos de los que 'sabía' o 'debería haber sabido', una obligación que se refuerza respecto a las personas o grupos en condiciones de extrema vulnerabilidad.

\section{B. Medidas Precautorias, Provisionales y Temporales}

Además de interpretaciones jurídicas específicas, en la arena de posturas más generales del derecho internacional de los derechos humanos, también se puede encontrar la primera aproximación general al 'riesgo' en la facultad procesal concedida a ciertas entidades jurídicas internacionales para emitir una orden de medidas precautorias, provisionales o temporales que suspenden el procedimiento con base en la necesidad de evitar un riesgo inminente de daño irreparable. Esta competencia procesal, frecuentemente utilizada tanto por el TEDH como por la $\mathrm{CIDH}^{32}$, evidencia la consideración del riesgo como una condición digna de evaluación jurídica que puede generar obligaciones positivas para el Estado.

Para proporcionar un ejemplo ilustrativo, puede hacerse referencia a un caso de la CIDH de 2000-2001 que concierne las expulsiones y deportaciones masivas de haitianos y dominicanos de origen haitiano por parte de las autoridades de República Dominicana, en situaciones en donde dicha acción ponía en riesgo la vida y la integridad física de aquellas personas deportadas, así como a los familiares que dejaron o dejarían atrás, especialmente aquellos menores abandonados como resultado de la expulsión. La Corte entonces emitió medidas precautorias y ordenó a República Dominicana adoptar todas las medidas necesarias para proteger la vida y la integridad personal de una serie de personas concretas y de abstenerse de deportar y expulsar de su territorio a uno de los niños involucrados en el caso. También ordenó al Estado permitir el regreso inmediato a su territorio a uno de los hombres afectados para hacer posible la reunificación entre él y su hijo ${ }^{33}$.

32 Véase GonZÁLEZ, F., «The Experience of the Inter-American Human Rights System», Victoria University Wellington Law Review, 40 (2009-10), 1, especialmente la sección D. Medidas urgentes en la Comisión y en la Corte, 123-24; y las estadísticas sobre solicitud y otorgamiento de medidas temporales (interim measures) por el TEDH de acuerdo con el artículo 43 del Convenio Europeo de Derechos Humanos y Libertades Fundamentales (CoEDH) en www.echr.coe.int; véase también Joint Dissenting Opinion of Judges Tulkens, Bonello and Spielmann en Nv UK, en el pie de página $\mathrm{n}^{\circ} 1$ ( $N$ v United Kingdom, Appl No 26565/05, 27 de mayo de 2008).

33 Véase CIDH, Medidas provisionales, haitianos y dominicanos de origen haitiano en la República Dominicana, Órdenes del 14 de septiembre de 2000; 12 de noviembre de 2000; y 26 de mayo de 
En este caso de medidas precautorias, la Corte consideró que existieron violaciones a los derechos de nacionalidad, personalidad jurídica y no discriminación, conclusión que sirvió de precedente para lo que después, en 2005, se convirtió en un caso contencioso de fondo ante la Corte en materia de género y personas no ciudadanas. El Caso de las Niñas Yean y Bosico v República Dominicana analizó la situación de dos hijas de migrantes irregulares haitianos en Dominicana a quienes se les negó el registro como personas nacidas en el país y por tanto, carecían de documentos para ingresar al colegio. En este caso la CIDH consideró que existieron violaciones a los derechos antes descritos, además de a los derechos de la niñez y el derecho a la educación ${ }^{34}$.

\section{Grupos especialmente vulnerables}

Tratándose de cuestiones de fondo, la CIDH también ha tratado con diferentes grupos especialmente vulnerables a violaciones de derechos humanos. En el Caso de los 'Niños de la Calle' (Villagrán Morales y otros) v Guatemala, de 1999, la Corte consideró que son niños especialmente vulnerables, aquellos que viven en situación de calle y aquellos identificados como niños en riesgo, una situación que obliga al Estado a tomar medidas positivas para mejorar su protección, de acuerdo con el artículo 19 de la Convención Americana sobre Derechos Humanos (CADH o Convención Americana), que se refiere a los derechos del niño, e interpretados a la luz de la Convención de NU sobre Derechos del Niño ${ }^{35}$.

Respecto de los hechos que involucraban el asesinato en 1990 de cinco niños de la calle, cuatro de ellos torturados, presumiblemente por policías en la

2001. Piénsese también en las medidas precautorias a nivel nacional dentro de los procedimientos jurídicos o constitucionales de protección a los derechos fundamentales, por ejemplo, a través de la suspensión de una orden de aprehensión que afecta el derecho a la libertad y seguridad, o de una orden de desalojo o desahucio relacionado con el derecho a la vivienda, en los que se involucran deberes negativos (de abstención/no hacer/no ejecutar) del Estado. Las órdenes de medidas precautorias también pueden requerir la intervención activa del Estado para proteger la vida o la integridad personal de un individuo y traducirla a obligaciones positivas que el Estado debe llevar a cabo.

34 Véase CIDH, Niñas Yean y Bosico v. República Dominicana, Sentencia del 8 de septiembre de 2005.

35 CIDH, Caso de los «niños de la calle» (Villagrán Morales y otros) v Guatemala, Sentencia del 19 de noviembre de 1999 (Méritos), paras. 185-91. Convención de NU sobre los Derechos del Niño, adoptada y abierta a firma, ratificación y adhesión por la Asamblea General, Resolución 44/25 del 20 de noviembre de 1989, y entrada en vigor el 2 de septiembre de 1990, de acuerdo con el artículo 19 . 
ciudad de Guatemala, la Corte concluyó con base en la Convención Americana sobre Derechos Humanos que el Estado violó los derechos del niño, así como sus obligaciones generales respecto a los derechos de la CADH (art. 1.1.) en relación con los derechos a la vida (art. 4), al trato humano (art. 5), y a la libertad personal (art. 7) de los niños; así como los derechos a un juicio justo y garantías procesales (art. 8.1) y a la protección judicial (art. 25) de las familias de los niños. También se consideró que estos graves acontecimientos constituyeron una violación al derecho de la integridad personal de acuerdo con los artículos 1, 6 y 8 de la Convención Interamericana para Prevenir y Sancionar la Tortura.

La Corte enmarcó las violencias sufridas por cada uno de los cinco niños y los miembros de sus familias en el contexto social más amplio existente al momento de los hechos, reconociendo:

«como un acto público y notorio que... hubo una práctica sistemática de agresión en contra de 'niños de la calle' en Guatemala llevada a cabo por miembros de fuerzas de seguridad del Estado; incluidas amenazas, persecución, tortura y desaparición forzada y homicidio» ${ }^{36}$.

Por tanto, la Corte Interamericana expandió el alcance de las obligaciones positivas de protección a casos en los que el Estado sabía o debería haber sabido de dichas situaciones de vulnerabilidad sistematizada. Este criterio, trabajado desde inicios de 1999, fue retomado por el sistema interamericano (tanto por la Comisión Interamericana de Derechos Humanos como por la Corte) en casos posteriores de violencia contra las mujeres de 2001 en adelante, y especialmente desde 2009 hasta la fecha, formulando obligaciones similares de prevención por parte del Estado a través de la noción de la 'debida diligencia'. Dicha noción trasciende la división tradicional público/privado para cubrir también la responsabilidad del Estado en casos de acciones llevadas a cabo por actores privados (por ejemplo, parejas o exparejas de mujeres víctimas de violencia) en las que el Estado no haya sido directamente el perpetrador de las violaciones ${ }^{37}$.

\footnotetext{
Caso de los «niños de la calle», op. cit., para. 189, énfasis añadido. Véase también paras 59 c) y 79.

37 Véase, eg, Comisión Interamericana de Derechos Humanos (CoIDH), Maria da Penha Maia Fernandes v Brazil, Caso 12,051, Informe No 54/01, Informe Anual, OEA/Ser.L/V.II.111 Doc 20 rev, 2000, 16 de abril de 2001; y los casos de la CIDH: Caso de González y Otros ('Campo Algodonero) v México, sentencia de 16 de noviembre de 2009 (Objeciones Preliminares, Fondo, Reparaciones y Costas); Inés Fernández Ortega y Otros v México (Ser C), nº 215, sentencia de 30 de agosto de 2010; y Valentina Rosendo Cantú y Otros v México (Ser C), n 216, sentencia de 31 de agosto de 2010 .
} 
Es posible por tanto identificar algunas expresiones más concretas de este punto de intersección de la relación seguridad humana-derechos humanos:

i. Obligaciones reforzadas de protección

La interpretación extensiva de la CIDH en el Caso de los Niños de la Calle $v$ Guatemala, utilizando la fórmula de cuando el Estado sabía o debería haber sabido, se encuentra también en línea con los principios generales de interpretación del Derecho Internacional Público. La Corte Interamericana indicó que cuando se interpreta un tratado, no sólo los acuerdos e instrumentos formalmente relacionados a él deben ser tomados en consideración (art. 31.2 de la Convención de Viena sobre el Derecho de los Tratados), sino también el sistema en sí en el que se encuentra inscrito dicho tratado (art. 31.3). La Corte relacionó los criterios utilizados de forma general en distintos sistemas jurídicos con el derecho internacional de los derechos humanos:

«que ha avanzado sustancialmente por la interpretación evolutiva de los instrumentos internacionales de protección... consecuente con las reglas generales de interpretación de los tratados plasmadas en la Convención de Viena de 1969... los tratados de derechos humanos son instrumentos vivientes, cuya interpretación debe evolucionar en el tiempo en vista de las circunstancias existentes».

Bajo este razonamiento, la Corte concluyó que tanto la Convención Americana sobre Derechos Humanos como la Convención de NU sobre los Derechos del Niño forman parte de un corpus juris internacional, esencial para la protección del niño, y que debe servir de apoyo para la Corte para establecer el contenido y alcance de la norma general establecida en el artículo 19 de la Convención Americana (relativo a los derechos de niños y niñas) ${ }^{38}$.

En su Opinión Conjunta Concurrente, los Jueces Cançado Trindade y Abreu-Burelli enfatizaron la interpretación de la CIDH y detallaron el razonamiento para una más amplia interpretación del alcance del derecho a la vida de los niños de la calle, como se deriva de la sentencia de la Corte:

«El deber del Estado para tomar medidas positivas se refuerza precisamente en relación con la protección de la vida de personas vulnerables e indefensas, en situación de riesgo, como los niños de la calle. La privación

38 Caso de los «niños de la calle» $v$ Guatemala, op. cit., paras 192-94. La sentencia se refiere de la Convención de Viena sobre el Derecho de los Tratados, adoptada en Viena el 23 de mayo de 1969, entrada en vigor el 27 de enero de 1980, Naciones Unidas, Series de Tratados, vol 1155, 2005, p. 331. 
arbitraria de la vida no se limita, pues, al acto ilícito de homicidio; se extiende igualmente a la privación del derecho a la vida digna. Esta perspectiva conceptualiza el derecho a la vida como un tema, al mismo tiempo, del dominio de los derechos civiles y políticos, así como de los derechos económicos, sociales y culturales, pues ilustra la interrelación e indivisibilidad de todos los derechos humanos» ${ }^{39}$.

El Caso de los Niños de la Calle v Guatemala de la CIDH resuena con las inquietudes expresadas por el Comité sobre los Derechos del Niño de NU, órgano a cargo de revisar el cumplimiento de los Estados Parte con la Convención sobre los Derechos del Niño y sus Protocolos Facultativos ${ }^{40}$. El Comité de NU ha señalado su preocupación (concretamente en la revisión del Estado de Togo) sobre la falta de medidas tomadas para asistir a los 'niños en riesgo', como el Comité les llama, incluyendo a niños viviendo en extrema pobreza o en la calle, de convertirse en víctimas de explotación sexual, pornografía y trata, de acuerdo con sus obligaciones de prevención enunciadas en el artículo 9, párrafos 1 y 2, del Protocolo Facultativo de la Convención sobre los Derechos del Niño relativo a la Venta de Niños, la Prostitución Infantil y la Utilización de Niños en la Pornografía. El Comité va más allá también para enfatizar los enlaces entre la discriminación basada en el género y la violencia como un terreno fértil para que los niños, y en particular las niñas, confronten el riesgo de explotación sexual. De hecho, analizando las obligaciones del Estado a este respecto, el Comité de NU específicamente recomendó que de conformidad con las normas de la Convención, el Estado debiera:

«Tomar medidas efectivas para identificar grupos de niños, incluyendo niñas, niños viviendo en pobreza extrema y niños en situación de calle, en riesgo de ser víctimas de violaciones prohibidas bajo el Protocolo Facultativo, y proporcionarles el apoyo y asistencia necesarios.

39 Caso de los «niños de la calle» v Guatemala, op. cit., Opiniones Conjuntas Concurrentes de los Jueces AA Cançado Trindade y A Abreu-Burelli, para 4. Énfasis agregado.

40 Artículos 43-45 de la Convención de NU sobre Derechos del Niño; artículo 8, párrafo 1, del Protocolo Facultativo de la Convención sobre los Derechos del Niño relativo a la participación de niños en conflictos armados; y artículo 12, párrafo 1, del Protocolo Facultativo de la Convención sobre los Derechos del Niño relativo a la venta de niños, la prostitución infantil y la utilización de niños en la pornografía, adoptado, firmado, y abierto a ratificación mediante Resolución A/RES/54/263 de la AGNU del 25 de mayo de 2000 y entrado en vigor el 18 de enero de 2002. 
Erradicar la discriminación basada en género y la violencia, y en particular derogar leyes aún en vigor que discriminan a las mujeres...» ${ }^{41}$.

Regresando al nivel interamericano, la Corte también ha determinado abiertamente la obligación del Estado de tomar medidas activas para abordar el riesgo en el campo de la vulnerabilidad socio-económica. En los casos de Moiwana v Surinam, Pueblo de Saramaka v Surinam, Yakye Axa v Paraguay, Sawhoyamaxa v Paraguay, y Xákmok Kásek v Paraguay, referidos a pueblos indígenas y comunidades tradicionales y resueltos entre 2005 y 2010, la Corte enfatizó el riesgo y la vulnerabilidad resultante de la extrema pobreza, junto con la pertenencia de personas a comunidades indígenas o grupos étnicos minoritarios. Consecuentemente, interpretó las obligaciones del Estado, respecto a los derechos a la vida, integridad personal y protección judicial, para englobar obligaciones positivas de mitigar las condiciones de riesgo para prevenir violaciones a derechos humanos y adoptar medidas protectoras para enfrentar dichas amenazas, afirmando así la obligación de protección reforzada del Estado. También otorgó amplia consideración al concepto comunal de propiedad de estos grupos indígenas como una condición que les permitiría enfrentar el riesgo y asegurar la posibilidad de sobrevivencia económica, basándose en su caso parteaguas de la Comunidad Awas Tingni v Nicaragua, de $2001^{42}$.

En el caso de la Comunidad Indígena Sawhoyamaxa v Paraguay de 2006, relativo a personas en situación de movilidad, especialmente a personas desplazadas internamente, el Juez Cançado Trindade incluso dio vida a un modo concreto de utilizar la simbiosis seguridad humana-derechos humanos a través de una interpretación judicial. En este caso, basado en un estudio académico sobre seguridad humana y dignidad humana, el Juez Cançado nos recuerda que:

«El problema de las personas desplazadas internamente... es en realidad un problema de derechos humanos. Las personas desplazadas están en una posición vulnerable precisamente debido al hecho de que están bajo

41 Comité de NU sobre Derechos del Niño, CRC/C/OPSC/TGO/CO/1, 8 de marzo de 2012, sesión cincuenta y nueve, llevada a cabo del 16 de enero al 3 de febrero de 2012, 'Consideración de informes presentados por los Estados Parte bajo el artículo 12, párrafo 1, del Protocolo Facultativo de la Convención sobre los Derechos del Niño relativo a la participación de niños en conflictos armados. Observaciones Finales: Togo', para 21, c) y d).

42 CIDH, Caso de Mayagna (Sumo) la Comunidad Awas Tingni v Nicaragua, sentencia del 31 de agosto de 2001 (Fondo, Reparaciones y Costas). 
la jurisdicción del Estado (su propio Estado) que no adoptó suficientes medidas para evitar o prevenir la situación de abandono virtual que sufrieron $\gg^{43}$.

De igual forma que el análisis hecho por la CIDH, el TEDH ha abordado la preocupación ante la vulnerabilidad y a la fecha ha identificado básicamente tres 'grupos vulnerables': las personas con discapacidad mental, la gente gitana, y los solicitantes de asilo ${ }^{44}$. Algunos de estos casos se refieren a elementos de discriminación por género y más notablemente, a violaciones a derechos humanos en relación con la raza, la etnia y/o el origen nacional. Revisemos algunas de estas evaluaciones del TEDH sobre vulnerabilidad grupal.

Como un caso ilustrativo, encontramos el de Connors v Reino Unido, donde el TEDH concluyó que había existido una violación al artículo 8 (vida privada y familiar) derivado del desalojo de un hombre gitano y su familia de un sitio de caravanas, considerando que existió una falta de protección del estilo de vida de los gitanos, y que no se tomó en cuenta la 'posición vulnerable de los gitanos como una minoría'. De igual modo, en Chapman v Reino Unido, el Tribunal concluyó que existía una obligación positiva del Estado, según el artículo 8 del Convenio Europeo de Derechos Humanos y Libertades Fundamentales $(\mathrm{CoEDH})$, de facilitar el estilo de vida de los gitanos.

En un caso más reciente, Aksu v Turquía, de 2012, el TEDH evaluó si Turquía había cumplido con su obligación positiva según el artículo 8 en la protección de la vida privada del solicitante de una supuesta interferencia por una tercera parte (el autor de un libro y dos diccionarios) que fue -de acuerdo con la demanda del solicitante- dañina y ofensiva hacia la comunidad gitana y su estilo de vida, y reflejo de sentimientos anti-gitanos racistas. En este caso, sin embargo, aun cuando el TEDH reconoció que 'la posición vulnerable de los gitanos significa que debe dársele una consideración especial a sus necesidades y sus diferentes estilos de vida, tanto en el marco regulatorio relevante como en

43 CIDH, Sawhoyamaxa v Paraguay, Opinión separada del Juez AA Cançado Trindade, apoyando su argumento en el trabajo de STAVRopoulou, M., «Searching for Human Security and Dignity: Human Rights, Refugees, and the Internally Displaced», en Danieli, Y.; STAMatopouLOU, E. y Dias, C. J. (eds.), The Universal Declaration of Human Rights: Fifty Years and Beyond, Baywood Publishing Co, Amityville, New York, 1999, 181-82; en para 14, nota al pie 20. Énfasis agregado.

44 Véase el excelente artículo por Peroni, L. y Timmer, A., «Vulnerable Groups: The Promise of an Emergent Concept in European Human Rights Convention Law», International Fournal of Constitutional Law, 11 (2013), 1056-85. 
las decisiones en casos particulares', concluyó que no había existido violación, ya que el Estado había balanceado adecuadamente el derecho del solicitante a una vida privada contra la libertad de expresión del autor, la cual prevaleció en la resolución final del caso ${ }^{45}$.

Cabe hacer notar que en el caso de Muñoz Díaz v España, de 2010, el TEDH había sostenido precisamente que 'la posición vulnerable de los gitanos significa que alguna consideración especial debe darse a sus necesidades y a sus diferentes estilos de vida, tanto en el marco regulatorio relevante como en las decisiones en casos particulares'. En esta instancia se concluyó que el Estado sí había incurrido en una violación, al vulnerar el artículo 14 del CoEDH (no discriminación) en relación con el artículo 1 del Protocolo 1 de la Convención (disfrute pacífico de posesiones) al negarle a una mujer gitana su derecho a una pensión sobre la base de no reconocer el matrimonio gitano con su difunto esposo (siendo que dicho matrimonio había sido aceptado como válido a través de varios actos por las autoridades españolas) ${ }^{46}$.

Por último, tratándose de las personas solicitantes de asilo como un grupo identificado como vulnerable por el TEDH, debe señalarse que tales personas se han enfrentado también a graves inseguridades humanas, según se reconocía desde el Informe de la Comisión de Seguridad Humana de 2003 y en estudios relativos, particularmente en el contexto posterior a los ataques terroristas del 11 de septiembre de 2001 en el caso de EE.UU. y a la crisis económica experimentada desde 2008 en Europa occidental y la actual crisis de refugiados, en su mayoría sirios, enfrentada en Medio Oriente y, en mucho menor medida, en la Unión Europea ${ }^{47}$.

En el ámbito, pues, de solicitantes de asilo, cabe destacar el caso de M.S.S. v Bélgica y Grecia, de 2011, en el que el TEDH consideró el traslado de un solicitante de asilo de origen afgano de Bélgica a Grecia (país por el que

45 Casos por el TEDH: Connors v Gran Bretaña, Appl No 66746/01, 27 de mayo de 2004, para 84 (énfasis agregado); Chapman v Gran Bretaña (GC), Appl No 27138/95, 18 de enero de 2001, paras 92 y 96; Aksu v Turquía (GC), Appl Nos 4149/04 y 41029/04, 15 de marzo de 2012, paras 75, 61, y 81-89. Énfasis agregado.

46 TEDH, Muñoz Díaz v España, Appl No 49151/07, 8 de diciembre de 2009 (Final 8 de marzo de 2010), paras 61 y 69-71. Enfasis agregado.

47 Véase Rojas Aravena, F. y Goucha, M. (eds.), FLACSO-Chile/UNESCO, Seguridad Humana, Prevención de Conflictos y Paz en América Latina y el Caribe, FLACSO-Chile, Santiago, Chile, 2002; FreITAS, R., «Human Security and Refugee Protection after September 11: A Reassessment», Refugee: Canada's Periodical on Refugees, 20 (2002), 4; y EDWARDS, A., «Human Security and the Rights of Refugees: Transcending Territorial and Disciplinary Borders», Michigan Fournal of International Law, 30 (2009), 3. 
originalmente había entrado a la UE), como una violación por parte de ambos países del artículo 3 de la CoEDH. Notablemente, el Tribunal llegó a esa conclusión bajo el argumento de que M.S.S. se encontraba en una situación de vulnerabilidad teniendo en cuenta su angustia individual, pero vista contra el telón de fondo de las condiciones sistémicas de pobreza y privación material que enfrentan los solicitantes de asilo en Grecia como un 'grupo de población vulnerable que necesita protección especial' ${ }^{148}$.

Sobre la base de estas consideraciones, el TEDH resolvió que la decisión de Bélgica de que el solicitante de asilo regresara a Grecia equivalía a una violación del artículo 3 de la CoEDH, referido al derecho a no ser sometido a tortura u otros tratos crueles, inhumanos o degradantes y a la prohibición de expulsión de una persona a un país en el que enfrente un riesgo de sufrir este trato (principio de no-devolución o non-refoulment). Del mismo modo, el Tribunal concluyó que las condiciones de vida precarias del demandante afgano en Grecia constituían una violación del artículo 3 por parte de dicho país ${ }^{49}$.

Sin embargo, pueden darse otros ejemplos sobre cuáles son las consecuencias de no aplicar una perspectiva de seguridad humana en el análisis jurídico de violaciones de derechos humanos, concretamente en el ámbito de los derechos humanos de las personas migrantes. En una sentencia anterior emitida también por el TEDH en 2008 en el caso de $N v$. Reino Unido, el Tribunal analizó la situación de una mujer de Uganda, que había llegado al Reino Unido con un pasaporte falso y, aunque ella no lo sabía en ese momento, era VIH-positivo. En el Reino Unido había recibido tratamiento de soporte médico vital que según los informes médicos, le permitiría vivir por una década. La mujer, $\mathrm{N}$, había sido rechazada como solicitante de asilo y en caso de ser deportada de regreso a Uganda, existía una fuerte evidencia para estimar que, debido a la falta de medicamentos antirretrovirales en el sistema de salud de Uganda, moriría dos años después de su regreso. El TEDH llegó a la conclusión de que la expulsión de $\mathrm{N}$ a Uganda no constituiría una violación por parte del Reino Unido de la obligación de no devolución contenida en el artículo 3 de la Convención Europea ${ }^{50}$.

48 M.S.S. v. Bélgica y Grecia, TEDH, No. 30696/09, 2011, para 251; véanse también paras 232 y 233.

49 Ibid., puntos 10 y 5 de la parte dispositiva de la sentencia. Para un caso que presenta esta misma línea de argumentación en el ámbito del Tribunal de Justicia de la Unión Europea, véase asuntos acumulados C 411/10 y C 493/10, NS y Otros v. SSHD, ECR, 2011.

50 N v. Reino Unido, TEDH, No. 26565/05, 2008, véanse los paras. 18 y 19. 
Este caso llama la atención pues más de diez años antes, en 1997, el TEDH había decidido exactamente lo contrario en el caso análogo de $D v$ Reino Unido. Este último caso se refería a un hombre VIH-positivo de Saint Kitts y Nevis que se enfrentaba una inminente deportación del Reino Unido, y al cual el Tribunal le otorgó la protección solicitada con base en el Art. 3 de la $\mathrm{CoEDH}$ argumentado la situación de particular vulnerabilidad en la que se hallaba la persona y el riesgo de sufrir trato inhumano o degradante que confrontaría ante la falta de atención médica adecuada al regresar a su país de origen $^{51}$.

Con respecto al caso de $N v$ Reino Unido, Eve Lester plantea que un resultado diferente podría haberse alcanzado por el TEDH si hubiera aplicado un enfoque de seguridad humana (como aquel de $D v$ Reino Unido), que habría hecho hincapié en el riesgo vital crítico enfrentado por $\mathrm{N}$, visto a la luz del contenido básico del derecho humano al más alto nivel posible de salud (en lugar del análisis estricto que hizo sólo considerando el contenido del artículo 3 sobre prohibición de la tortura). Ella argumenta que las decisiones judiciales que integraran la visión de seguridad humana en su análisis podrían obligar a los Estados a traducir su retórica en resultados reales que aumentarían la accesibilidad y la disponibilidad de los medicamentos antirretrovirales en el mundo en desarrollo, donde el peso de la pandemia del VIH/SIDA tiene visos de permanecer por varios años más ${ }^{52}$. Tal vez una perspectiva de esta naturaleza adoptada por el Tribunal Europeo de Derechos Humanos habría estado realmente a la altura del compromiso de hacer valer el derecho humano a la salud de $\mathrm{N}$ y en última instancia su derecho a la vida, ante el riesgo inminente de perderla.

\section{ii. Discriminación indirecta e inversión de la carga probatoria}

La vulnerabilidad y la discriminación no deben confundirse, esta última siendo una distinción real injustificada, mientras que la vulnerabilidad se sitúa

51 TEDH, D v Reino Unido, Appl No 30240/96, 2 de mayo de 1997.

52 Para un análisis detallado de este caso, así como el caso similar de $D v$ Reino Unido, véase LesTER, E., «Socio-economic rights, human security and survival migrants: Whose rights? Whose security?», en Edwards, A. y Ferstman, C., Human Security and Non-Citizens: Law, Policy and International Affairs, Cambridge University Press, Cambridge, 2010. Véase también por el TEDH el caso más reciente de $S \mathcal{f} v$ Bélgica, donde se llegó a un acuerdo amistoso con vistas a proteger a una mujer migrante indocumentada originaria de Nigeria y afectada de VIH-SIDA, para no ser expulsada de Bélgica (No. 70055/10. Solución amistosa: agosto 2014. Gran Sala: 2015). 
en el ámbito de lo posible o lo susceptible. Según el derecho internacional de los derechos humanos, la discriminación se puede entender como cualquier distinción, exclusión, restricción o preferencia u otro trato diferencial que está directa o indirectamente basado en los ámbitos prohibidos de la discriminación y que tiene la intención o el efecto de anular o menoscabar el reconocimiento, disfrute o ejercicio, en un plano igual, de derechos humanos y libertades fundamentales. Dichos ámbitos prohibidos de discriminación incluyen el sexo, el género, la raza, el color, la descendencia, la cultura, el idioma, la religión, la opinión política, el origen nacional o étnico, el estatus migratorio, la discapacidad o cualquier otro estatus que se tome en cuenta con la intención o el efecto mencionado ${ }^{53}$.

Existen casos que nos recuerdan, sin embargo, que un mayor nivel de exposición a factores de riesgo, es decir, la vulnerabilidad, podría en sí misma considerarse como discriminación, especialmente en casos de discriminación indirecta. En el caso prominente de DH y Otros v República Checa, el TEDH entendió el concepto de discriminación indirecta al examinar si la colocación altamente desproporcionada de estudiantes gitanos en escuelas de aprendizaje para personas con discapacidad ('escuelas especiales') en República Checa constituía una violación de su derecho, según el artículo 2 del Protocolo 1 (derecho a la educación) leído en conjunto con el artículo 14 (no discriminación) del CoEDH, para ser libres de discriminación racial en el ámbito de la educación. El Tribunal concluyó sobre esa base que el Estado había sido responsable de dichas violaciones y que tenía una obligación positiva de proteger a los gitanos como un pueblo vulnerable. El TEDH enfatizó que la discrimi-

53 Comité de NU sobre Derechos Económicos, Sociales y Culturales (Comité DESC de NU), Observación General No 20, No-Discriminación en los Derechos Económicos, Sociales y Culturales (art. 2, para. 2), E/C.12/GC/20, 10 de junio de 2009, para 7, en combinación con las definiciones de discriminación del Art. 1 de la Convención Internacional para la Eliminación de la Discriminación Racial de 1965; el Art. 1 de la Convención para la Eliminación de la Discriminación contra la Mujer de 1979; y el Art. 2 de la Convención de NU sobre Derechos de las Personas con Discapacidad de 2008. El Comité de Derechos Humanos de NU, revisor del PIDCP, proporciona una interpretación similar en su Observación General No 18, paras 6 y 7. Sobre el derecho a la no-discriminación por estatus migratorio, véase también Comité de NU sobre la Eliminación de la Discriminación Racial, Recomendación General No.30: Discriminación contra No-Ciudadanos: 01/10/2004 (Observaciones Generales), disponible en 'Compilation of General Comments and General Recommendations adopted by Human Rights Treaty Bodies. Addendum', HRI/GEN/1/Rev.7/Add.1, 4 de mayo de 2005, así como las Observaciones Generales 1 y 2 del Comité de NU sobre los Derechos de Todos los Trabajadores Migratorios y sus Familiares. 
nación significa tratar de un modo diferente, sin un objetivo o justificación razonable, a personas en situaciones relativamente similares. El Tribunal puntualizó que la:

«'falta de objetivos y justificación razonable' significa que la diferencia en trato impugnada no persigue un 'objetivo legítimo' o que no hay una 'relación razonable de proporcionalidad' entre los medios empleados y el objetivo que se quiere realizar» ${ }^{54}$.

Sin embargo, en ocasiones esta atención por el Tribunal a grupos vulnerables no ha sido uniforme o totalmente coherente, especialmente y preocupantemente respecto a casos de violencia contra el pueblo gitano ${ }^{55}$.

En el caso del TEDH de Horváth y Kiss v Hungría, de enero de 2013, la Corte encontró una violación al derecho a la educación en relación con el derecho a la no discriminación, siguiendo la línea de DH y Otros, en este caso afectando a dos hombres gitanos que cuando niños habían sido colocados en 'escuelas especiales' a cuenta de una 'ligera discapacidad mental.' En este caso, el Tribunal señaló que los niños gitanos habían sido sobre-representados entre los alumnos en la primaria de regularización y la escuela vocacional de los solicitantes y que los niños gitanos habían sido en general sobre-representados en el pasado en escuelas de regularización en Hungría debido a un diagnóstico sistemáticamente equivocado de experimentar discapacidad mental. Las estadísticas básicas no fueron discutidas por el gobierno húngaro. El TEDH indicó que esta situación debía ser vista en el contexto de una larga historia de malas colocaciones de niños gitanos en escuelas especiales en Hungría y otros países europeos. Mientras que podría argumentarse que la situación resultante de que los solicitantes fueran tratados de modo diferente -la colocación con base en su evaluación escolar- pudo haber tenido un efecto similar en otros grupos socialmente desventajados, según el Tribunal existía no obstante, a primera vista, un caso de discriminación indirecta en contra de los niños gitanos. Por tanto, el gobierno tuvo que probar que esa diferencia en trato no tuvo efectos desproporcionalmente perjudiciales para los niños gitanos. El TEDH concluyó que los niños gitanos habían sido 'mal diagnostica-

54 Véase TEDH, DH y Otros v República Checa (GC), Appl No 57325/00, 13 de noviembre de 2007, paras 181, 175 y 196. Traducción propia.

55 Véase Möschel, M., «Is the European Court of Human Rights' Case Law on Anti-Roma Violence "Beyond Reasonable Doubt"?», Human Rights Law Review, 3, 12 (2012), 479-507, para un recuento de la renuencia del TEDH de abordar estos casos como casos de discriminación racial al amparo del Art. 14 del CoEDH, así como la tabla ilustrativa proporcionada en la p. 483. 
dos debido a su desventaja socio económica y a diferencias culturales.' En línea con las valoraciones de la seguridad humana, la sentencia contiene incluso una sección dedicada a analizar el 'contexto social' del caso ${ }^{56}$.

Mientras que este caso es un 'buen caso' en términos de igualdad y no discriminación por etnicidad y otorga debida consideración al contexto de vulnerabilidad experimentada por el pueblo gitano, existen algunos puntos débiles que nos hacen calificarlo como un 'caso cuestionable' en términos de respeto a los derechos humanos de las personas con discapacidad ${ }^{57}$.

Con respecto a la vulnerabilidad específica de personas con discapacidad mental, el TEDH también ha basado su evaluación de esta condición en la 'historia pasada de discriminación y de prejuicio' contra esta población y ha aclarado que ello resulta en obligaciones reforzadas para el Estado cuando aplica limitaciones a los derechos de estas personas. En el caso de Alajos Kiss v Hungría, se indica que:

«[S]i una restricción a los derechos fundamentales se aplica a un grupo particularmente vulnerable en la sociedad, que ha sufrido discriminación considerable en el pasado, como el de las personas con discapacidad mental, entonces el margen de apreciación del Estado es sustancialmente más estrecho $\mathrm{y}$ debe de tener razones suficientemente fuertes para las restricciones en cuestión... [E]l trato como una clase única de aquellas personas con discapacidad mental o intelectual es una clasificación cuestionable y la restricción de sus derechos debe ser sujeta a un estricto escrutinio» ${ }^{58}$.

Así pues, aparte de reforzar las obligaciones de protección en el contexto de vulnerabilidad social estructural, este acercamiento también mantiene el efecto de reducir el margen de apreciación disponible al Estado. Convergiendo con el enfoque de seguridad humana, la priorización debe ser enfocada a los derechos de aquellos que son los más vulnerables y no al espacio de interpretación discrecional del Estado, aun cuando dicha opción legal se encuentra generalmente disponible.

56 TEDH, Horváth y Kiss v Hungría, Appl No 11146/11, 29 de enero de 2013, paras 104,105 y 115; y sección 1.B. Traducción propia.

57 Por ejemplo, la calificación de los colegios para niños y niñas con discapacidad mental como 'inferiores' (para 115). La sentencia tampoco mencionó en ningún momento la Convención de NU sobre Derechos de las Personas con Discapacidad, de la cual es parte la Unión Europea desde 2010, un análisis que se antojaba necesario dadas las circunstancias del caso (véase, eg, paras. 72-76).

58 TEDH, Alajos Kiss v Hungría, Appl No 38832/06, 20 de mayo de 2010, paras 42 y 44. Traducción propia. Énfasis agregado. 
Sin embargo, la identificación de ciertas vulnerabilidades legitima una excepción a este margen legal y desencadena una inversión de la carga probatoria hacia el Estado, ya que descansa en este actor la justificación del trato diferencial hacia el grupo vulnerable o sus miembros. En otras palabras, es el Estado quien tiene que probar que no trató de manera discriminatoria a la persona miembro de un grupo vulnerable o al grupo mismo, y no el denunciante de un trato (injustificadamente) diferenciado quien debe probar dicha circunstancia. La inversión de esta carga probatoria respecto a personas en situación de vulnerabilidad extrema y urgente, se ha reafirmado también por el Comité DESC de NU, el cual ha abordado el tema en otros casos generales de vulnerabilidad estructural y/o discriminación ${ }^{59}$.

\section{Estereotipo y Daño Colectivo: Respuestas Colectivas}

Desde una perspectiva más amplia relativa a la vulnerabilidad de otros grupos, cabe notar que el fenómeno de estereotipar colectivamente, demonizando o criminalizando a ciertos grupos, a través de focalizar o destacar ciertas características de los miembros de un grupo -reales o supuestas-, requeriría respuestas que tomen en cuenta la dimensión colectiva de la situación de un grupo vulnerable. Tristemente, ciertas expresiones de estereotipo colectivo han tomado forma en algunas medidas oficiales de gobierno, exactamente lo contrario a lo que exige el derecho internacional de los derechos humanos, por ejemplo, en el caso de la expulsión colectiva del pueblo gitano (Roma) por el gobierno francés en 2011, que parece repetirse en algunas políticas de deportación revisadas por la CIDH en el caso de haitianos y dominicanos de origen haitiano expulsados de República Dominicana, mencionado anteriormente.

Es cierto que el derecho internacional de los derechos humanos y el derecho internacional público en general han respondido a lo anterior con la protección de los derechos de la colectividad misma, y no sólo del individuo o del individuo en cuanto miembro del grupo. Puede pensarse, por ejemplo, en el derecho a la tierra comunal utilizada por los pueblos indígenas -un 'derecho de propiedad colectiva'- según el artículo 26 de la Declaración de NU de los Derechos de los Pueblos Indígenas de 2007. Este tipo de protección

59 Véase a este respecto Comité DESC de NU, Observación General No 20, No-Discriminación en los Derechos Económicos, Sociales y Culturales (art. 2, para 2), E/C.12/GC/20, 10 de junio de 2009; y Pisarello, G., «Los derechos humanos de los migrantes», en AÑón, M ${ }^{a} \mathrm{~J}$. (ed.), La universalidad de los derechos sociales: el reto de la inmigración, Tirant lo Blanch, Valencia, 2004. 
también ha tomado forma a través del derecho penal internacional en el régimen protector del Convenio para la Prevención y la Sanción del Delito del Genocidio de 1948 y, cincuenta años después, en el Estatuto de Roma de la Corte Penal Internacional de 1998, relativo a grupos nacionales, étnicos, religiosos y lingüísticos. $\mathrm{Al}$ mismo tiempo, el derecho internacional y otros regímenes normativos a nivel regional y nacional toman en cuenta la pertenencia a ciertos grupos como uno de los elementos para fundamentar el derecho a la no discriminación o para adoptar medidas directas de protección entendidas ampliamente como un mecanismo para la igualdad sustantiva ${ }^{60}$.

A nivel de NU se contempla la protección de los derechos de las minorías en el artículo 27 del Pacto Internacional de Derechos Civiles y Políticos de 1966 (PIDCP) y el artículo 30 de la Convención de los Derechos del Niño de 1989, y especialmente, en la Declaración sobre los Derechos de las Personas Pertenecientes a Minorías Nacionales o Étnicas, Religiosas y Lingüísticas de 1992; aunque en todos estos casos el derecho debe ser ejercido individualmente por el miembro del grupo (y no por un ente colectivo). Asimismo, como se indicó anteriormente, el TEDH ha abordado el tema de la vulnerabilidad colectiva principalmente respecto de ciertos grupos como el pueblo gitano, los solicitantes de asilo o las personas con discapacidad ${ }^{61}$. Por su parte, la CIDH ha profundizado en el análisis de la vulnerabilidad socio-económica como una característica transversal que transciende membresías nacionales, étnicas, religiosas o lingüísticas ${ }^{62}$. La región interamericana fue también pionera en considerar la violencia contra mujeres como un problema endémico que requería un régimen normativo específico, materializado en la Convención Interamericana para la Prevención, Sanción y Erradicación de la Violencia contra las Mujeres (Convención de Belém do Pará), de 1994.

Sin embargo, parecería que ciertas acciones políticas o sociales de estereotipación colectiva presentes en regímenes autoritarios, pero también en sistemas democráticos, especialmente en tiempos de crisis económicas, evaden los regímenes normativos existentes o se escapan de la normatividad clásica del derecho internacional de los derechos humanos.

60 Véase LeRner, N., Group Rights and Discrimination in International Law, $2^{\mathrm{a}}$ ed., Brill-Martinus Nijhoff Publishers, La Haya, 2005.

61 Peroni, L. y Timmer, A., «Vulnerable Groups...», op. cit.

62 Véase, eg, Caso de la Comunidad Indígena Xákmok Kásek v Paraguay, Fondo, Reparaciones y Costas, sentencia del 24 de agosto de 2010; y Pueblo Saramaka v Surinam, Objeciones Preliminares, Fondo, Reparaciones, y Costas, sentencia del 28 de noviembre de 2007. 
Frente a estas expresiones de estereotipo colectivo que tocan de manera cercana las fronteras de la discriminación racial o étnica, se necesita también una respuesta colectiva. Ésta debería atender la situación más allá de considerar la suma de sufrimientos o violaciones individuales a derechos humanos, $\mathrm{y}$ más bien incorporar una postura que pondere y conecte debidamente estas dimensiones colectivas. Una de las posibilidades para adoptar dicha postura de alcance colectivo se ofrece en la concepción de seguridad humana, entendida en los términos de la definición más precisa del informe de 2003 de la Comisión de Seguridad Humana (CSH), Human Security Now, que aborda los riesgos 'críticos' y 'generalizados', y complementada por la Resolución de la AGNU de 2012 que coloca a todos los derechos humanos -civiles, políticos, económicos, sociales y culturales- en el centro de la seguridad humana. Una manera de implementar esta definición es utilizando las políticas públicas con un enfoque basado en el binomio seguridad humana-derechos humanos, pues estas medidas del Poder Ejecutivo constituyen una herramienta arquetípica para abordar problemas 'macro' de una naturaleza amplia y colectiva.

Algunas decisiones judiciales internacionales, por ejemplo, el caso Muñoz Díaz v España del TEDH, antes revisado, han empezado (un tanto tímidamente) a referirse a los marcos regulatorios (propios del Derecho Administrativo) como posibles instrumentos necesarios para proteger a grupos en condición de vulnerabilidad y facilitar su estilo de vida -en este caso el estilo de vida de una familia gitana-, y consecuentemente el ejercicio de derechos.

La relación entre políticas públicas y el cumplimiento de derechos humanos también ha empezado a desdoblarse a través de la inclusión en ciertos instrumentos normativos regionales de amplio rango, de obligaciones relativas a los derechos de las mujeres; es el caso de la Convención del Consejo de Europa sobre prevención y lucha contra la violencia contra la mujer y la violencia doméstica, la Convención de Estambul, que además de incluir la obligación del Estado de adoptar políticas 'sensibles al género' en materia de 'igualdad entre mujeres y hombres y empoderamiento de las mujeres' (art. 6), también incluye todo un capítulo sobre la obligación de los Estados de adoptar 'Políticas integradas y recolección de información' para prevenir y combatir la violencia contra las mujeres ${ }^{63}$.

63 Convenio del Consejo de Europa sobre prevención y lucha contra la violencia contra la mujer y la violencia doméstica, abierto a firma y ratificación en Estambul el 11 de mayo de 2011, y entrado en vigor el 1 de agosto de 2014. 


\section{Algunas conclusiones: la SEguridad humana COMO Catalizador del Derecho Internacional Público}

La idea de seguridad humana construida internacionalmente converge con el derecho internacional público en varios aspectos, de manera notoria con el derecho internacional de los derechos humanos, el humanitario, el penal internacional, y el derecho internacional de los refugiados, por los valores y principios que todos ellos defienden.

$\mathrm{El}$ análisis rector de este texto, centrado en el DIDH a modo de ejemplificar algunas aplicaciones concretas de la interacción seguridad humanaderechos humanos, ha revelado la posibilidad que ofrece este binomio de producir interpretaciones jurídicas más progresistas y expansivas. Con ello puede añadirse valor tanto al concepto de seguridad humana como al de los derechos humanos, y en última y más importante instancia, conceder mayores y más eficientes protecciones a las persones que sufren situaciones de vulnerabilidad estructural en nuestra sociedad mundial actual.

Se presentan al lector o lectora de forma resumida algunas de las intersecciones concretas de este binomio, a fin de evaluar de forma más clara los puntos de encuentro entre la seguridad humana y el Derecho Internacional Público:

- Las normas y casos revisados reflejan una creciente toma de conciencia de la interconexión entre la seguridad humana y la protección de los derechos humanos, mediante la interpretación expansiva de ciertos derechos con base en consideraciones sensibles a la seguridad humana.

- La seguridad humana permite abordar riesgos y vulnerabilidades generalizadas y colectivas que de otro modo permanecerían invisibles o serían analizadas de forma aislada mediante un examen tradicional de derechos humanos individuales, y no de manera interrelacionada como se presentan de hecho en la realidad social.

- En consecuencia, facilita la formulación de políticas públicas con perspectiva de derechos humanos, siendo la política pública el instrumento arquetípico para abordar situaciones 'macro'. Ello ya comienza a sugerirse en expresiones normativas del Consejo de Europa, por ejemplo, en torno a los derechos humanos de las mujeres.

- La seguridad humana posibilita posturas de prevención y atención más integrales ante la discriminación y estereotipación colectiva, incitando las interpretaciones que protejan a todos los miembros del grupo afectado, tanto de daños potenciales ('derechos en riesgo') como ante violaciones 
materializadas que vulneren derechos humanos concretos. Ello abre el camino incluso para la determinación de reparaciones colectivas que trasciendan la dimensión puramente individual de las violaciones.

- La simbiosis seguridad humana-derechos humanos ha empujado a la Corte Interamericana de Derechos Humanos a expandir el alcance de las obligaciones positivas de protección a casos en los que el Estado sabía o debería haber sabido de situaciones de vulnerabilidad colectiva y sistematizada que la suma de varios derechos humanos individuales no alcanzan a cubrir.

- Por su parte, aplicando igualmente lo que pudiera llamarse una 'visión sensible a la seguridad humana', el Tribunal Europeo de Derechos Humanos ha afirmado la existencia de obligaciones reforzadas de protección en casos que involucran riesgos colectivos afectando a personas en situación de pobreza, a población gitana, a personas con discapacidad mental y a solicitantes de asilo.

- A la luz de la 'hoja de ruta' que propone el concepto de seguridad humana y los desafíos globales e interrelacionados que hace visibles (a efecto de nuestro examen, eg, la vulnerabilidad socio-económica y la pobreza, los riesgos sufridos por niños y niñas, especialmente aquellos en situación de calle, o la distribución mundial de personas solicitantes de asilo, migrantes y refugiadas) se facilitan las interpretaciones más amplias de derechos 'tradicionales' como el derecho a la vida o la integridad personal, pero también argumentaciones que tiendan a una expansión judicial de los DESC, incluyendo, por ejemplo, el derecho a la educación o la salud, en combinación con el derecho a la igualdad y la no-discriminación.

- La seguridad humana puede presentar un sano reto a las concepciones clásicas de soberanía, ciudadanía y derechos abordados por el Derecho Internacional Público ${ }^{64}$. En efecto, el derecho internacional, incluyendo el DIDH, construido sobre una lógica centrada en el Estado, afecta críticamente a varias categorías de personas que experimentan un 'vacío de ciudadanía', tales como las personas migrantes indocumentadas y aquellas solicitantes de asilo.

64 Véase en este sentido GüNDOĞDu, A., Rightlessness in an Age of Rights: Hannah Arendt and the Contemporary Struggles of Migrants, Oxford University Press, 2015, 3, 197; y BRYSK, A. y Gershon, S., People Out of Place: Globalization, Human Rights, and the Citizenship Gap, Routledge 2004. 
- Como ventaja estratégica y postura metodológica, el lente de la seguridad humana aplicado al derecho internacional público, en particular de los derechos humanos, abre la puerta para un diálogo jurídico más cercano entre los sistemas europeo e inter-americano de derechos humanos, como se evidencia de las normas y casos judiciales revisados.

- El binomio seguridad humana-derechos humanos internacionales sirve para promover, con base en la axiología común de la dignidad humana, un Estado de derechos y no sólo un Estado de Derecho, que proteja y respete a todas las personas, particularmente a aquellas que sufren vulnerabilidad añadida. 